\title{
Consultório na Rua: o Olhar dos Estudantes de Medicina de uma Liga Acadêmica de Alagoas
}

\author{
Dantas, Lourena Gonçalves; Melo Neto, Valfrido Leão de; Gitaí, Lívia Leite Goes; \\ Cruz, Filipe Jonas Federico da; Sousa, Welison de Lima; Anjos, Camilla Gonçalves \\ dos
}

Universidade Federal de Alagoas (Ufal) —lourena13@hotmail.com

INTRODUÇÃo Os projetos de extensão universitária no campo da saúde são dispositivos acadêmicos importantes para a formação humanística dos futuros profissionais dessa área. Este trabalho relata a experiência de estudantes de medicina de uma liga acadêmica que vivenciaram o "Consultório na Rua" na cidade de Maceió - Alagoas, uma equipe multiprofissional de trabalho itinerante, que atende pessoas em situação de rua in loco, buscando prestar atenção integral à saúde MÉTODOS Duplas de integrantes da liga acadêmica foram revezadas em ciclos práticos de 3 semanas para que acompanhassem o trabalho da equipe volante do Consultório na Rua pela cidade de Maceió. Antes da saída do grupo para os campos de atuação, as duplas verbalizaram suas expectativas. Depois do trabalho, as duplas relataram suas experiências e impressões. RESULTADOS o estado de vulnerabilidade das pessoas em situação de rua foi identificado ao encontrar indivíduos com comprometimento do estado geral ou pessoas em uso ou expostas ao álcool, crack e outras drogas. Durante os atendimentos da equipe, foi identificado o exercício da redução de danos à saúde por meio das ações interdisciplinares: escuta qualificada, orientações em saúde, cuidados básicos de enfermagem e distribuição dos insumos de prevenção. a conduta de acolhimento da equipe fortaleceu vínculos de confiança com a população em situação de rua, o que facilitou os diálogos entre os atores sociais. Esses diálogos eram orientados no sentido da promoção da saúde e da articulação para o acesso da população a outros setores do sistema de saúde, aos albergues e à assistência social, uma vez que as ações do Consultório na Rua são integradas à Unidade Básica de Saúde e a outros serviços, a depender da necessidade do usuário. Algumas pessoas participavam ativamente dessa interlocução com a equipe e com os estudantes, de modo que as reações emocionais e as promessas que surgiam revelavam que os diálogos motivam essas pessoas para o cuidado com a própria saúde. Foram acompanhados relatos de indivíduos que buscaram ativamente os serviços aos quais foram encaminhados pela equipe. Outras pessoas eram resistentes, configurando-se como perfis desafiadores para o atendimento, porém o discurso do grupo sempre garantia o suporte constante. Essa dinâmica de integração com os indivíduos em situação de rua mostra então o perfil integral e longitudinal da assistência. CONCLUSÕES Os estudantes puderam observar no projeto de extensão exemplos de sucesso no acesso a serviços de saúde pela população em situação de rua, através do vínculo estabelecido entre os usuários e a equipe interdisciplinar do Consultório na Rua, cujo discurso inclusivo e encorajador motivou a procura e a adesão a tratamentos. por fim, a experiência nesse projeto mostra um impacto para a formação humanística de profissionais médicos, pois há uma vivência da relação médico-paciente, a partir do conceito ampliado de saúde, em um cenário de práticas que exige mais dinamismo: o espaço das ruas.

Dantas, Lourena Gonçalves; Melo Neto, Valfrido Leão de; Gitaí, Lívia Leite Goes; Cruz, Filipe Jonas Federico da; Sousa, Welison de Lima; Anjos, Camilla Gonçalves dos. Consultório na Rua: o Olhar dos Estudantes de Medicina de uma Liga Acadêmica de Alagoas. In: Anais do Congresso Internacional de Humanidades \& Humanização em Saúde [= Blucher Medical Proceedings, num.2, vol.1]. São Paulo: Editora Blucher, 2014. ISSN 2357-7282

DOI 10.5151/medpro-cihhs-10370 